\title{
Territorialidade, políticas públicas e o agronegócio com foco no desenvolvimento
}

\author{
Anderson Catapan \\ catapan@utfpr.edu.br \\ Universidade Tecnológica Federal do \\ Paraná, Curitiba, Paraná, Brasil. \\ Antonio Gonçalves de Oliveira \\ agoliveira@utfpr.edu.br \\ Universidade Tecnológica Federal do \\ Paraná, Curitiba, Paraná, Brasil.
}

\section{EDITORIAL}

Este editorial apresenta os artigos do terceiro número do sexto volume da Revista Brasileira de Planejamento e Desenvolvimento (RBPD). Este número trouxe contribuições para o planejamento e desenvolvimento, assim como em números anteriores e já de praxe deste periódico, de professores do Brasil e de diversos outros países.

O primeiro artigo de Burchardt (2017) analisa o neoextrativismo e o desenvolvimento. Depois, Traub e Myszczuk (2017) fazem um estudo sobre territorialidade e formação do servidor no contexto da metrópole.

Em seguida, Baron de Vargas (2017), em robusta discussão teórica, analisa o sentido de discutir políticas públicas sob a perspectiva das regiões, sob o pano de fundo do Plano "Brasil sem Miséria". No quarto artigo, Martins, Parreira e Veira (2017) abordam a importância da infraestrutura de transporte para o desenvolvimento do estado de Goiás.

O próximo artigo, assinado por Konan e Blanco (2017) apresenta uma discussão sobre o massacre de Grand-Bassam e seus impactos econômicos e sociais do terrorismo na Costa do Marfim. No sexto artigo de Valenga e Ribaski (2017) é apresentada uma avaliação da ergonomia e da renda com a conversão do cultivo de morango no solo para semi-hidropônico. Depois, Costa et al. (2017) analisam a gestão das atividades de produção do Sururu em Alagoas, considerando um caso de utilização de ferramentas e técnicas de gestão de projetos. Por ultimo, Elizabeth e Umoh (2017) fazem uma abordagem de experiência de estudantes indianos e relações inter-raciais na Universidade de Kwazulu-Natal.

Aproveitamos para comunicar para a comunidade que a RBPD foi recentemente indexada na base de dados REDALYC. Vamos avançando em relação à indexações de alto nível, com o objetivo de sempre maximizar a qualidade da revista.

Apresentados os artigos deste número, desejamos uma ótima e proveitosa leitura a todos!!! 